\title{
Light Down-Converter Based on Luminescent Nanofibers from the Blending of Conjugated Rod-Coil Block Copolymers and Perovskite through Electrospinning
}

\author{
Dai-Hua Jiang ${ }^{1,2,3}$, Saburo Kobayashi ${ }^{3}$, Chih-Chun Jao ${ }^{1}$, Yoshinobu Mato ${ }^{3}$, Takuya Isono ${ }^{4}$, \\ Yu-Han Fang ${ }^{1}$, Chun-Che Lin ${ }^{1}{ }^{1}$, Toshifumi Satoh ${ }^{4, * \mathbb{D}}$, Shih-Huang Tung ${ }^{2, *}$ and \\ Chi-Ching Kuo $1, * \mathbb{B}$ \\ 1 Institute of Organic and Polymeric Materials, Research and Development Center of Smart Textile Technology, \\ National Taipei University of Technology, Taipei 10608, Taiwan; d06549013@ntu.edu.tw (D.-H.J.); \\ a405292005@gmail.com (C.-C.J.); au102324018@gmail.com (Y.-H.F.); cclin0530@gmail.com (C.-C.L.) \\ 2 Institute of Polymer Science and Engineering, National Taiwan University, Taipei 106, Taiwan \\ 3 Graduate School of Chemical Sciences and Engineering, Hokkaido University, Sapporo 060-8628, Japan; \\ saburou_k@eis.hokudai.ac.jp (S.K.); mato@eis.hokudai.ac.jp (Y.M.) \\ 4 Faculty of Engineering, Hokkaido University, Sapporo 060-8628, Japan; isono.t@eng.hokudai.ac.jp \\ * Correspondence: satoh@eng.hokudai.ac.jp (T.S.); shtung@ntu.edu.tw (S.-H.T.); kuocc@mail.ntut.edu.tw \\ (C.-C.K.); Tel.: +886-2-27712171 (ext. 2407) (C.-C.K.); Fax: +886-2-27317174 (C.-C.K.)
}

Received: 25 November 2019; Accepted: 1 January 2020; Published: 3 January 2020

\begin{abstract}
We demonstrated a novel strategy for the preparation of light down-converter by combining rod-coil block copolymers with perovskite quantum dots (QDs) through electrospinning. Reports have shown that polymer deformability can be enhanced by incorporating a soft segment and controlled by varying the rod/coil ratio. Therefore, we first synthesized the rod-coil block copolymer through the click reaction of polyfluorene (PF) and poly ( $n$-butyl acrylate) (PBA). Next, the $\mathrm{CsPbBr}_{3} @ \mathrm{PF}_{8 \mathrm{k}}-b-\mathrm{PBA}_{12 \mathrm{k}}$ composite fibers were fabricated by blending perovskite through electrospinning. Optical spectral evidence demonstrated the success of the strategy, as light down-converters were prepared through the controlled variance of $\mathrm{QD} /$ polymer ratios to achieve tunable color and stretchability. This result reveals the potential of using rod-coil block copolymers to fabricate color-tunable perovskite light down-converters.
\end{abstract}

Keywords: rod/coil block copolymer; perovskite; polymer; electrospinning; light down-converter

\section{Introduction}

Several organic semiconducting materials have been studied due to their potential beneficial properties, such as solution processability [1,2], band gap tuning [3-5], chemical structure, and self-assembly [6,7]. Satisfactory intrinsic active materials must be able to sustain large mechanical deformation and maintain high semiconducting properties for use in stretchable optical devices due to the growth of artificial intelligence technology [8-11]. With the growing enthusiasm for bioinspired robotics and healthcare wearables, it is essential to develop materials that can be flexible under high deformation and adhere to irregular surfaces [12-15]. Therefore, conjugated polymers incorporating elastomeric materials provide promising opportunities for satisfying current requirements. Several methods, including polymer blending [16-19], embedding [20,21], and chemical modification [22,23], have been widely utilized to enhance the stretchability and flexibility of materials. For example, Bao et al. [24] revealed a potential material based on 3, 6-di(thiophen-2-yl)-2,5-dihydropyrrolo [3,4-c] 
pyrrole-1,4-dione (DPP) backbone, which could maintain high field-effect mobility $\left(1.12 \mathrm{~cm}^{2} \mathrm{~V}^{-1} \mathrm{~s}^{-1}\right)$ under $100 \%$ strain. It can fully recover after damage via a solvent and thermal healing treatment due to network cross-linking with hydrogen bonding. Furthermore, the polymer structure strongly affects the device performance in the solid-state film; thus, rod-coil copolymerization based on a conjugated polymer with elastomeric polymer is considered a promising approach. Subsequently, our lab developed a series of block copolymers, such as: poly(3-hexylthiophene)-block-poly(n-butyl acrylate) (P3HT- $b$-PBA) and polyfluorene-block-poly(pendent isoindigo) (PF- $b$-Piso) for stretchable field-effect transistor and resistive memory applications $[25,26]$. In both of the cited studies, the materials were designed and synthesized through the copper-catalyzed azido-alkyne click reaction, which is widely used for the synthesis of block copolymers. The studies have shown that electronic properties and interchain organizations could be tuned by varying the rod/coil ratio [27,28]. However, the studies have mainly focused on stretchable field-effect transistors and memory devices [28,29], whereas stretchable light-emitting materials have received less attention.

Polyfluorenes (PFs) with different unit copolymers have been extensively used for efficient light-emitting diodes (LEDs) or light down-converters. This is because it is well-known for having blue-emitting conjugated moiety with inherent advantages, such as efficiency hole carrier transport, color tuning, effective thermal ability, and outstanding photoluminescence quantum yields (PLQYs) $[30,31]$. Thus, PF-based block copolymers are more beneficial for producing organic optoelectronic devices [32,33]. The strong $\pi-\pi$ stacking interchain interaction attributed to conjugated chains can be the driving force behind the formation of self-assembled nanostructures with crystalline order. This could affect the charge transport properties and performance of optoelectronic devices [27]. Recent studies have used fluorene copolymer for elucidating changes of packing structure and affecting fluorene structure in terms of optoelectronic and charge transport properties by different annealed states of different units [34,35]. Mo et al. utilized PF homopolymer derivative and carbazole grafting silafluorene for blue LEDs and revealed high external quantum efficiency $(4.1 \%)$ and high-quality deep blue emissions [CIE coordinates $(0.16,0.08)][34,35]$. However, the major drawback of utilizing homopolymer PF is its vulnerability when stretched due to its rigidity. To address this problem, our lab incorporated soft segments into block copolymers to enhance their stretchability. The thin film, consisting of poly [2, 7-(9, 9-dihexylfluorene)]-block-poly(n-butyl acrylate) (PF- $b$-PBA), could form obvious self-assembled nanofibrillar structures after solvent annealing treatment [27]. Moreover, the stretchability and optical properties of the materials were controllable by adjusting the rod/coil segment ratio. However, the optical and device performance of such designed materials decreased upon a coil ratio increase; this was due to a decrease in the conjugated phase domains [25,26]. Therefore, intrinsically stretchable light-emitting materials with high device performance that can operate under high mechanical strain, are necessary for the future.

Versatile soft materials have been combined with perovskite in stretchable LED devices or light down-converters [36-38]. For example, Mandal et al. reported on methylammonium lead bromide $\left(\mathrm{CH}_{3} \mathrm{NH}_{3} \mathrm{PbBr}_{3}\right)(\mathrm{MAPbBr})$ being introduced to poly (vinylidene fluoride) (PVDF) nanofiber through electrospinning. Electroactive phase composition can enhance the output power and tensile strength of the nanofiber mats [39]. In our previous work, composite $\mathrm{CsPbX}_{3}(\mathrm{X}=\mathrm{Cl}, \mathrm{Br}$, and I) perovskite nanocrystals (NCs) were encapsulated with stretchable [poly(styrene-butadiene-styrene); SBS] fibers by electrospinning on light down-converters. This was maintained for longer than $1 \mathrm{~h}$ in water and the material was stretched under $170 \%$ strain without obvious cracks showing; furthermore, the LED chip device still maintained high luminance and performance under low voltage [38]. Numerous studies have aimed to discover novel approaches for fabricating a white light-emitter with perovskite [40,41]. Fabrication processes for different colors of perovskite could even be implemented by adjusting halide components. The white light-emitter based on perovskite still needs to be used in full-color displays [38,42-44]. Therefore, multilayer by different colors for applying to white light-emitter is the conventional strategy but is complicated and troublesome. Encouraged by previous reports, in this paper we report on stretchable and blue light-emitter rod-coil di-block copolymers 
(PF- $b$-PBA) blended with perovskite $\left(\mathrm{CsPbBr}_{3}\right)$ to make nanofiber membranes through electrospinning on light down-converters. The rod-coil di-block copolymers (PF- $b$-PBA) were synthesized through the click reaction with ethynyl-terminated PF and azido-terminated PBA homopolymers, in accordance with a previous study [27]. To increase the viscosity of the di-block copolymers, which facilitates electrospinning, we synthesized PF-b-PBA with high molecular weight by combining Suzuki-Miyaura coupling polymerization for the PF block and atom transfer radical polymerization (ATRP) for the PBA block. Owing to the multifunction of electrospinning, we applied on an LED chip by using a nanofiber mat, which we fabricated via electrospinning [45-51]. The effects of the nanofiber mat prepared through electrospinning from $\mathrm{PF}-b$-PBA blended with perovskite $\left(\mathrm{CsPbBr}_{3}\right)$ were analyzed for deformation morphology and optical properties by using optical microscopy, UV-visible spectrometry, spectrofluorometry (PL), and confocal microscopy. In addition, we employed electrospinning to develop white-light-emitting fibers that can be color tuned by varying the perovskite/PF ratio. This work represents an authoritative stride in the field of perovskite electronics by opening new possibilities for white-light-emitting down-converter devices.

\section{Results and Discussion}

To prepare rod-coil block copolymers via the copper-catalyzed click reaction, first, the homopolymer with appropriate functional groups were synthesized in accordance with previous reports [31]. A benzyl alcohol-terminated polyfluorene $\left(\mathrm{PF}_{8 \mathrm{k}}-\mathrm{BnOH}\right)$ was synthesized using Suzuki-Miyaura coupling polymerization and then modified to the alkynyl-terminated PF $\left(1\right.$, alkyne- $\left.\mathrm{PF}_{8 \mathrm{k}}\right)$ through esterification with 5-hexynoic acid. The ${ }^{1} \mathrm{H}$ NMR spectra of the $\mathrm{PF}_{8 \mathrm{k}}-\mathrm{BnOH}$ and $\mathrm{PF}_{8 \mathrm{k}}-\mathrm{C} \equiv \mathrm{CH}$ clearly show the shift in the benzyl proton (from $4.80 \mathrm{ppm}$ to $5.24 \mathrm{ppm}$ ) and appearance of new signals due to the hexynoate moiety (f: 2.55, h: 2.32, i: 2.00, and g: 1.92 ppm) after the modification, which indicated the successful synthesis of $\mathrm{PF}_{8 \mathrm{k}}-\mathrm{C} \equiv \mathrm{CH}$ (Figure S1). The azido-terminated PBA was produced through atom transfer radical polymerization (ATRP) using 2-bromo-2methylpropanoate as the initiator. Subsequently, sodium azide was utilized to convert the bromo-terminated group to the azido group. The ${ }^{1} \mathrm{H}$ NMR spectra of azido-terminated PBA $\left(2, \mathrm{PBA}^{-\mathrm{N}_{3}}\right)$ backbone (a: 1.82-1.95 and b: 2.15-2.41 ppm) and butyl side chain (c: 3.89-4.08, $\mathrm{d}$ and e: 1.45-1.65, and f: $0.85-0.97 \mathrm{ppm}$ ) are depicted in Figure S2. The structures of the PBA were further confirmed by the FTIR spectrum (Figure S3). The FTIR spectrum of the PBA displayed a characteristic stretching band at $2100 \mathrm{~cm}^{-1}$, which corresponds to the azido group. Finally, the rod-coil block copolymer, poly [2, 7-(9, 9-dihexyl-fluorene)]-block-poly( $n$-butyl acrylate) (PF- $b$-PBA), was synthesized by coupling ethynyl-terminated PF with azido-terminated PBA; the synthetic pathway is illustrated in Scheme 1. The molecular characteristics of polymers are listed in Table 1 . Similarly, the ${ }^{1} \mathrm{H}$ NMR signals of $\mathrm{PF}_{8 \mathrm{k}}-b-\mathrm{PBA}_{12 \mathrm{k}}$ exhibited the same characteristic protons of long alkyl chain from both the PF and PBA segments, and the peak at $2100 \mathrm{~cm}^{-1}$ due to presence of the azido group completely disappeared from the FTIR spectrum (Figure 1). In addition, the SEC traces of the polymers (Figure S4) displayed a unimodal peak with the $M_{\mathrm{w}} / M_{\mathrm{n}}$ value of 1.43 , which clearly shifted toward a higher molecular weight region compared with that of the homopolymer owing to the successful coupling reaction. 

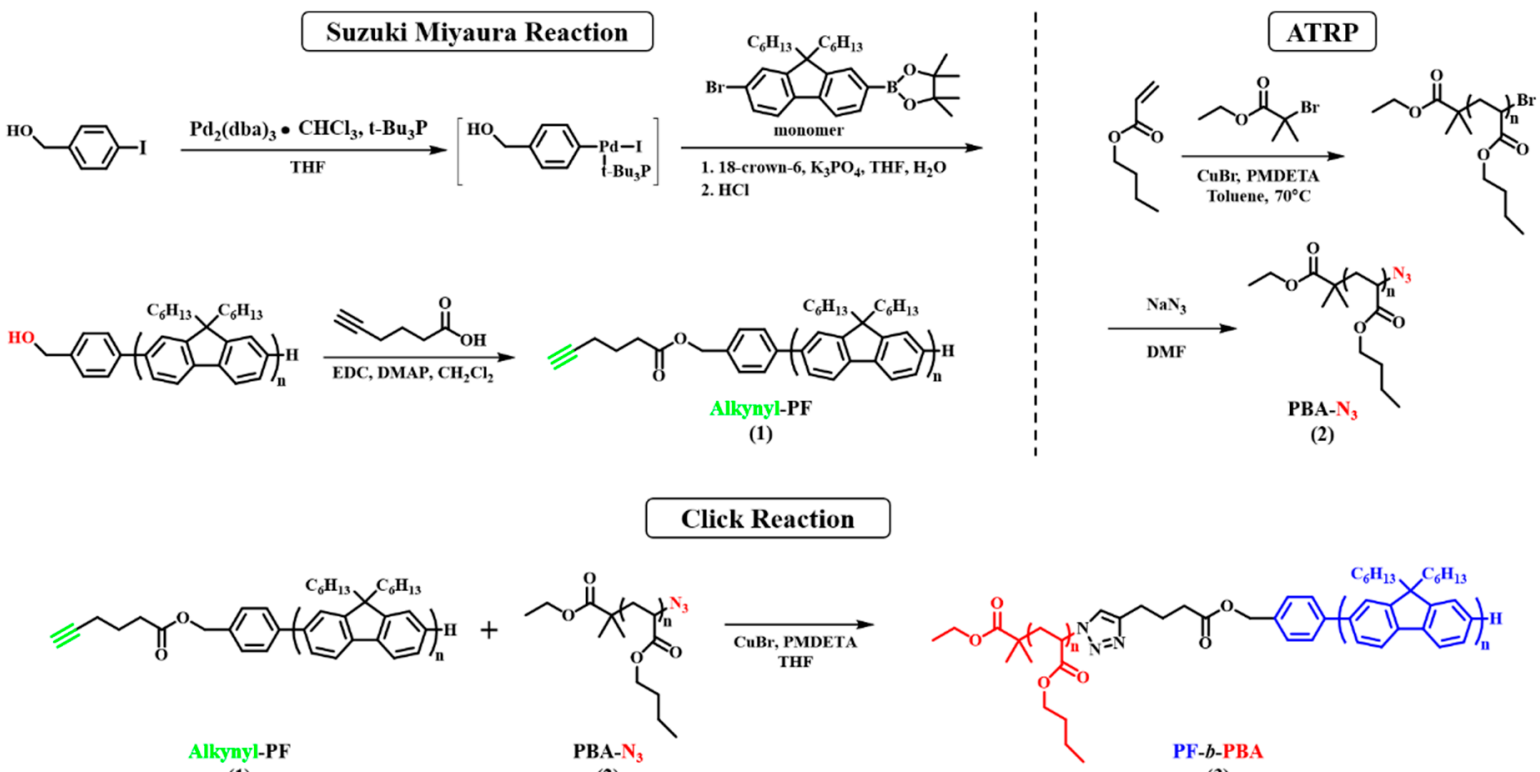

(1)

(2)

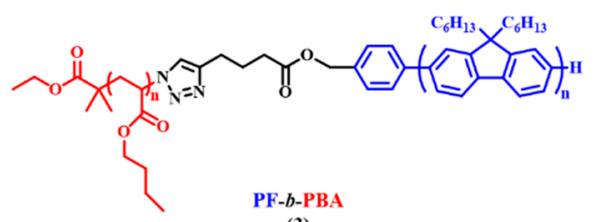

(3)

Scheme 1. Synthetic route for PF- $b$-PBA rod-coil block copolymer.

(a)

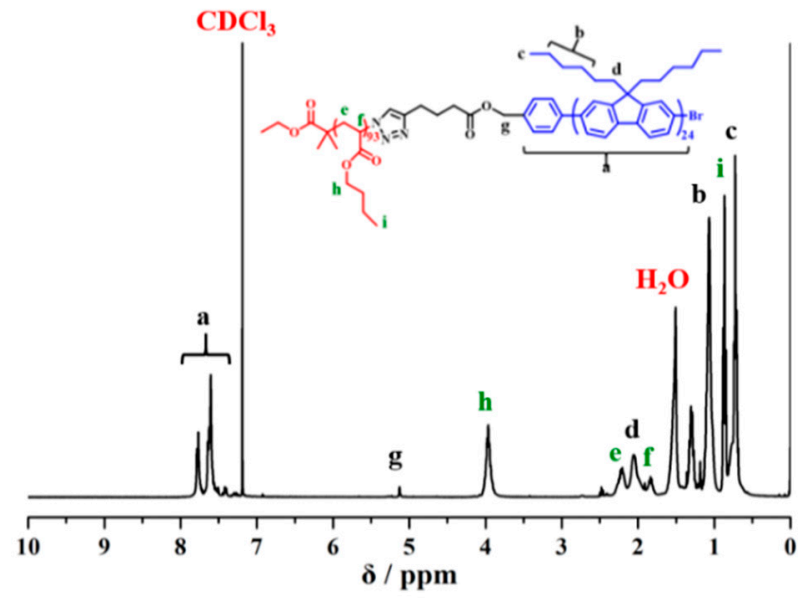

(b)

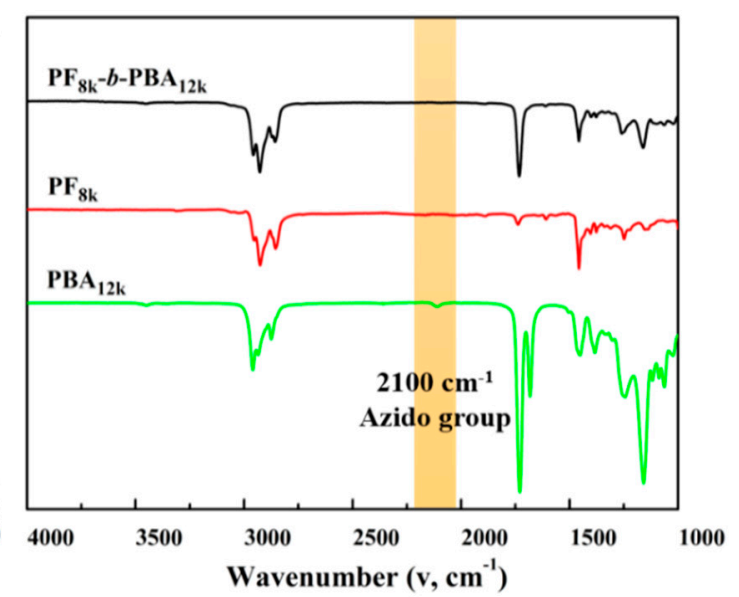

Figure 1. (a) ${ }^{1} \mathrm{H}-\mathrm{NMR}$ spectrum of the $\mathrm{PF}_{8 \mathrm{k}}-b-\mathrm{PBA}_{12 \mathrm{k}}$ in $\mathrm{CDCl}_{3}$ and (b) FTIR spectra of the $\mathrm{PF}_{8 \mathrm{k}}$, $\mathrm{PBA}_{12 \mathrm{k}}-\mathrm{N}_{3}$ and $\mathrm{PF}_{8 \mathrm{k}}-b-\mathrm{PBA}_{12 \mathrm{k}}$ copolymers.

Table 1. Molecular characteristics of the $\mathrm{PF}_{8 \mathrm{k}}, \mathrm{PBA}_{12 \mathrm{k}}-\mathrm{N}_{3}$ and $\mathrm{PF}_{8 \mathrm{k}}-b-\mathrm{PBA}_{12 \mathrm{k}}$ copolymers.

\begin{tabular}{|c|c|c|c|c|}
\hline Sample & PBA $^{a}\left(w t^{\%} \%\right)$ & $M_{\mathrm{n}, \mathrm{NMR}}{ }^{a}\left(\mathrm{~g} \mathrm{~mol}^{-1}\right)$ & $M_{\mathrm{n}, \mathrm{SEC}}{ }^{b}\left(\mathrm{~g} \mathrm{~mol}^{-1}\right)$ & $M_{\mathrm{w}} / M_{\mathrm{n}}{ }^{b}$ \\
\hline $\mathrm{PF}_{8 \mathrm{k}}$ & 0 & 8200 & 9400 & 1.38 \\
\hline $\mathrm{PBA}_{12 \mathrm{k}}-\mathrm{N}_{3}$ & 100 & 11,700 & 12,500 & 1.10 \\
\hline $\mathrm{PF}_{8 \mathrm{k}}-b-\mathrm{PBA}_{12 \mathrm{k}}$ & 72 & 19,100 & 21,400 & 1.43 \\
\hline
\end{tabular}

Next, we investigated the thermal behavior of the polymers by using TGA and DSC; the results are summarized in Table 2 . We reveal that the thermal degradation temperature $\left(T_{d}, 95 \%\right.$ weight loss) of the $\mathrm{PF}_{8 \mathrm{k}}-b-\mathrm{PBA}_{12 \mathrm{k}}\left(350^{\circ} \mathrm{C}\right)$ is in between the $\mathrm{PF}_{8 \mathrm{k}}\left(401^{\circ} \mathrm{C}\right)$ and $\mathrm{PBA}_{12 \mathrm{k}}-\mathrm{N}_{3}\left(340{ }^{\circ} \mathrm{C}\right)$ homopolymers, which shows favorable thermal stability(Figure S5). Moreover, the $\mathrm{PF}_{8 \mathrm{k}}-b-\mathrm{PBA}_{12 \mathrm{k}}$ exhibited two glass transition temperatures $\left(T_{g}\right)$ that are from individual homopolymers: $78{ }^{\circ} \mathrm{C}\left(\mathrm{PF}_{8 \mathrm{k}}\right)$ and $-54{ }^{\circ} \mathrm{C}$ $\left(\mathrm{PBA}_{12 \mathrm{k}}-\mathrm{N}_{3}\right)$. The individual phase transitions from PF and PBA are due to the incompatibility between 
the rod PF and the coil PBA phase; these tend to separate into different domains, resulting in the presence of two $T_{g}$ values [27].

Table 2. Physical properties of the $\mathrm{PF}_{8 \mathrm{k}}, \mathrm{PBA}_{12 \mathrm{k}}-\mathrm{N}_{3}, \mathrm{PF}_{8 \mathrm{k}}-b-\mathrm{PBA}_{12 \mathrm{k}}$ and $\mathrm{CsPbBr}_{3} @ \mathrm{PF}_{8 \mathrm{k}}-b-\mathrm{PBA}_{12 \mathrm{k}}$ $(1 \mathrm{~g} / 400 \mu \mathrm{L})$.

\begin{tabular}{cccccc}
\hline \multirow{2}{*}{ Sample } & \multirow{2}{*}{$\boldsymbol{T}_{\boldsymbol{d}}\left({ }^{\circ} \mathrm{C}\right)$} & $\boldsymbol{T}_{\boldsymbol{g}}\left({ }^{\circ} \mathrm{C}\right)$ & \multicolumn{2}{c}{ As-Cast Film } & Nanofiber Membrane \\
\cline { 4 - 6 } & & & $\lambda^{\text {abs }}{ }_{\max }(\mathbf{n m})$ & $\lambda^{\mathrm{PL}_{\text {max }}(\mathbf{n m})}$ & $\lambda^{\mathrm{PL}_{\text {max }}(\mathbf{n m})}$ \\
\hline $\mathrm{PF}_{8 \mathrm{k}}$ & 401 & 78 & 384 & 451,481 & - \\
$\mathrm{PBA}_{12 \mathrm{k}}$ & 340 & -54 & - & - & - \\
$\mathrm{PF}_{8 \mathrm{k}}-b-\mathrm{PBA}_{12 \mathrm{k}}$ & 350 & $-78,110$ & 386 & 445,466 & 446 \\
$\mathrm{CsPBB}_{3} @ \mathrm{PF}_{8 \mathrm{k}}-b-\mathrm{PBA}_{12 \mathrm{k}}$ & - & - & 382 & $445,471,510$ & 446,518 \\
\hline
\end{tabular}

The SEM images of $\mathrm{CsPbBr}_{3} \mathrm{QDs}_{\mathrm{P}} \mathrm{PF}_{8 \mathrm{k}}-b-\mathrm{PBA}_{12 \mathrm{k}}$ composite fibers $(1 \mathrm{~g}$ block copolymer and $400 \mu \mathrm{L}$ perovskite dissolve in $2 \mathrm{~mL} \mathrm{CH}_{2} \mathrm{Cl}_{2}$ ) prepared by electrospinning are presented in Figure $2 \mathrm{a}, \mathrm{b}$. The fabricated fibers are uniform and show average diameters of $8-10 \mu \mathrm{m}$. Moreover, their surface morphology is smooth, indicating that no perovskite crystals appeared on the fiber surface. Figure 2c shows the XRD data of the $\mathrm{CsPbBr}_{3} @ \mathrm{PF}_{8 \mathrm{k}}-b-\mathrm{PBA}_{12 \mathrm{k}}$ fiber $(1 \mathrm{~g} / 400 \mu \mathrm{L})$ compared with $\mathrm{CsPbBr}_{3} @ \mathrm{PF}_{8 \mathrm{k}}-b-\mathrm{PBA}_{12 \mathrm{k}}(1 \mathrm{~g} / 400 \mu \mathrm{L})$ and $\mathrm{CsPbBr}_{3}$ QDs films. The $\mathrm{CsPbBr}_{3} @ \mathrm{PF}_{8 \mathrm{k}}-b-\mathrm{PBA}_{12 \mathrm{k}}$ film and $\mathrm{CsPbBr}_{3} @ \mathrm{PF}_{8 \mathrm{k}}-b-\mathrm{PBA}_{12 \mathrm{k}}$ fiber did not show any perovskite peak. We speculate that this is due to theinside of the fiber. Therefore, we conducted confocal imaging for $\mathrm{CsPbBr}_{3} \mathrm{QDs}_{\mathrm{CPF}} \mathrm{Pk}_{\mathrm{k}}-b-\mathrm{PBA}_{12 \mathrm{k}}$ that was excited by ultraviolet (UV) light at a wavelength of $380 \mathrm{~nm}$, as shown in Figure 2d. The perovskite and the PF in the sample emitted their original light colors, which verified that they retained their fluorescent properties after electrospinning and that the perovskite QDs were encapsulated inside the polymer fiber. The UV-vis absorption and PL emission of the polymers prepared by spin coating and electrospinning are summarized in Table 2. The photophysical property of their corresponding solution is presented in Figure S6. In the case of the as-cast film, the $\lambda^{\text {abs }}$ max values of $\mathrm{PF}_{8 \mathrm{k}}$ and $\mathrm{PF}_{8 \mathrm{k}}-b-\mathrm{PBA}_{12 \mathrm{k}}$ were observed at 384 and $386 \mathrm{~nm}$ due to the $\pi-\pi$ conjugation of the PF segment. Concerning the as-cast film of $\lambda^{\mathrm{PL}}{ }_{\max }$ values, we can clearly observe the blueshift from $\mathrm{PF}_{8 \mathrm{k}}-b-\mathrm{PBA}_{12 \mathrm{k}}$, a phenomenon which could explain the phase separation from the PF and PBA segment. The blueshift was due to the aggregation of the PF phase. For the as-cast film of $\mathrm{CsPBr}_{3} @ \mathrm{PF}_{8 \mathrm{k}}-b-\mathrm{PBA}_{12 \mathrm{k}}$, the $\pi-\pi$ conjugation peak was also observed at $382 \mathrm{~nm}$, and the $\lambda^{\mathrm{PL}}{ }_{\max }$ values showed peaks at 445,471 , and $510 \mathrm{~nm}$, respectively. The distinct peaks of 445 and $471 \mathrm{~nm}$ relate to the different crystal phases of the PF and the peak of $510 \mathrm{~nm}$ is from the $\mathrm{CsPbr}_{3}$ QDs. 
(a)

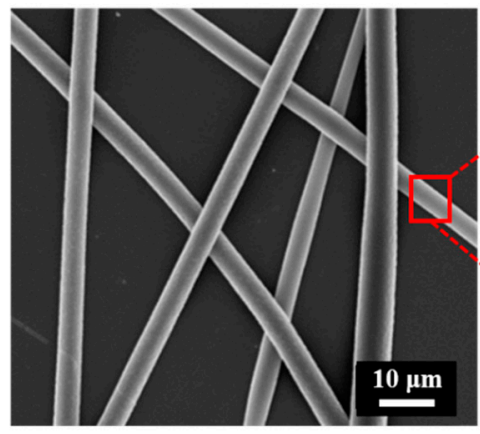

(c)

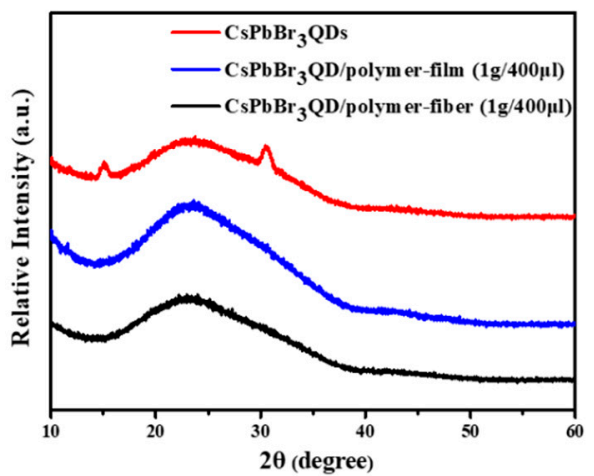

(b)

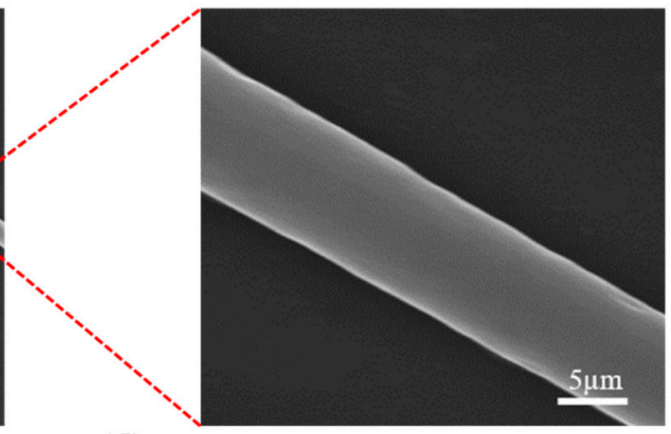

(d)

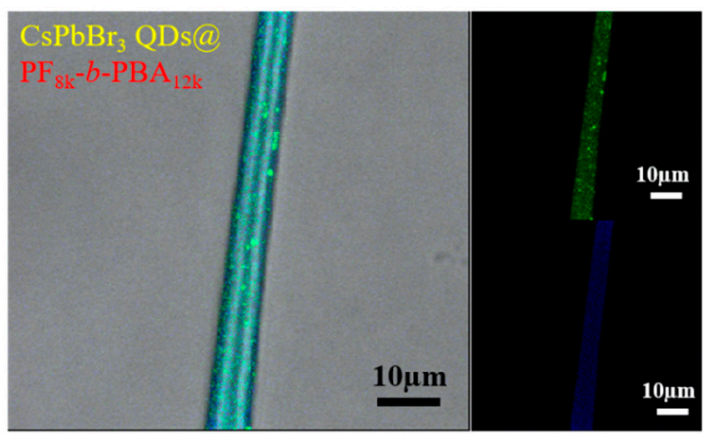

Figure 2. (a,b) SEM images of the $\mathrm{CsPbBr}_{3} @ \mathrm{PF}_{8 \mathrm{k}}-b-\mathrm{PBA}_{12 \mathrm{k}}$ fibers $(1 \mathrm{~g} / 400 \mu \mathrm{L})$. (c) XRD patterns of the $\mathrm{CsPbBr}_{3} @ \mathrm{PF}_{8 \mathrm{k}}-b-\mathrm{PBA}_{12 \mathrm{k}}$ fiber compared with $\mathrm{CsPbBr}_{3} @ \mathrm{PF}_{8 \mathrm{k}}-b-\mathrm{PBA}_{12 \mathrm{k}}$ and $\mathrm{CsPbBr}_{3} \mathrm{QD}$ film. (d) Confocal image of the $\mathrm{CsPbBr}_{3} \mathrm{QDs}_{\mathrm{P}} \mathrm{PF}_{8 \mathrm{k}}-b-\mathrm{PBA}_{12 \mathrm{k}}$ fibers.

The deformation of the $\mathrm{PF}$ homopolymer, $\mathrm{PF}_{8 \mathrm{k}}-b-\mathrm{PBA}_{12 \mathrm{k}}$ block copolymer film, and $\mathrm{CsPbBr}_{3}$ QDs@PF $\mathrm{Pk}_{8 \mathrm{k}}-b$-PBA ${ }_{12 \mathrm{k}}$ composite fibers $(1 \mathrm{~g} / 400 \mu \mathrm{L})$ were measured directly using an optical microscope under different strains, as shown in Figure 3. The polymer samples were prepared onto the polyurethane (PU) substrate by spin coating and electrospinning. All unstrained samples were observed without any cracks. By contrast, in the $\mathrm{PF}_{8 \mathrm{k}}$ homopolymer sample, the cracks continuously enlarged as the strain increased. Due to the incorporation of the PBA soft segment, the stretchability of $\mathrm{PF}_{8 \mathrm{k}}-b-\mathrm{PBA}_{12 \mathrm{k}}$ block copolymer was clearly enhanced. In addition, the stretchability of $\mathrm{CsPbBr}_{3} \mathrm{QDs}_{\mathrm{OPF}} \mathrm{Pk}_{\mathrm{k}}-b-\mathrm{PBA}_{12 \mathrm{k}}$ composite fibers exhibited good deformability even under $100 \%$ strain. However, the $\mathrm{PF}_{8 \mathrm{k}}-b-\mathrm{PBA}_{12 \mathrm{k}}$ film started to crack when the strain reached $150 \%$. By contrast, the CsPbBr 3 QDs@PF $\mathrm{Pk}_{8 \mathrm{k}}-b-\mathrm{PBA}_{12 \mathrm{k}}$ fiber membrane exhibited no cracks even under $200 \%$ strain. This confirms that coil segment modification and nano-scale change by electrospinning can effectively enhance the stretchability of material [52,53]. 


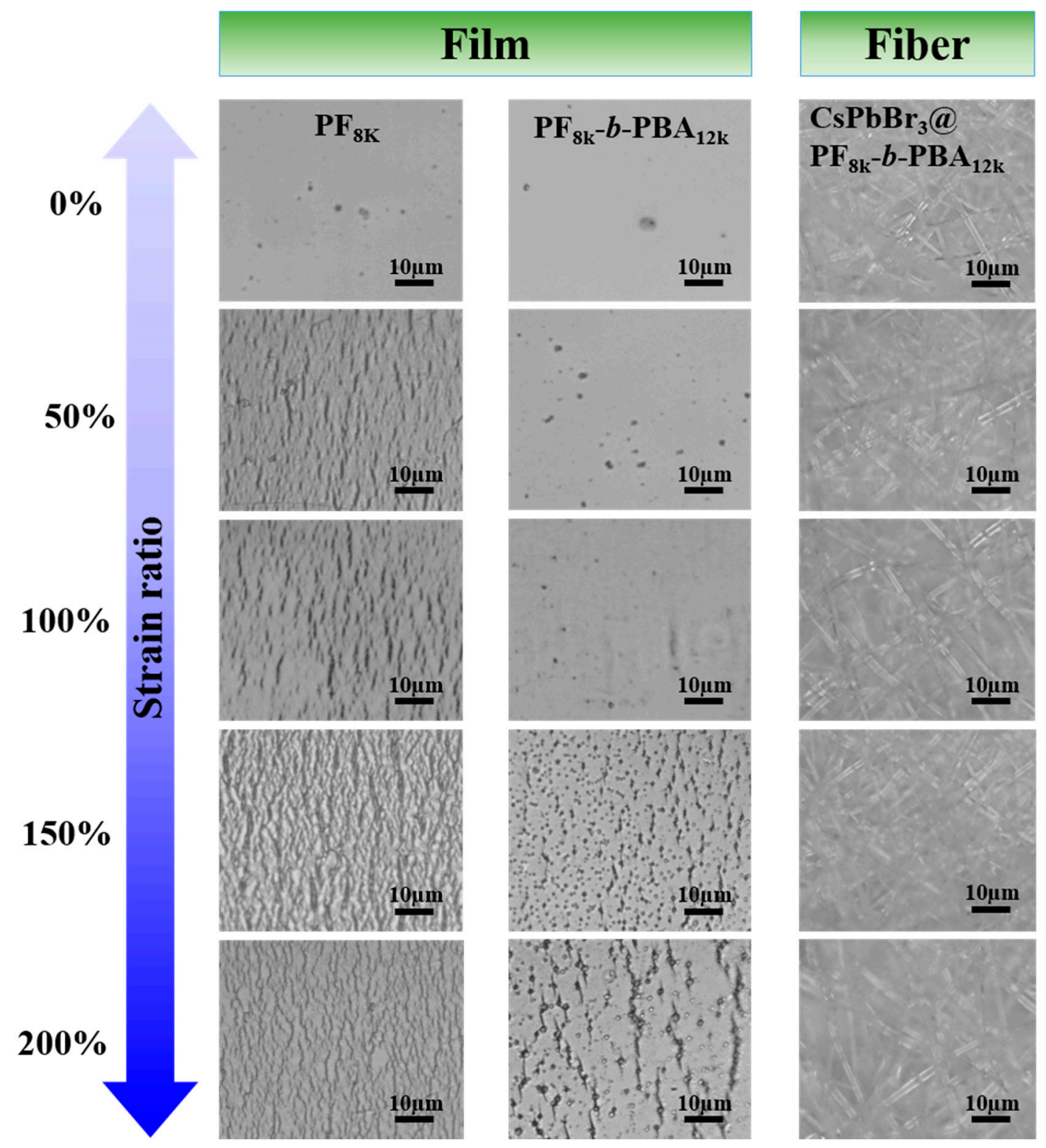

Figure 3. The crack-onset test for the $\mathrm{PF}_{8 \mathrm{k}}$ and $\mathrm{PF}_{8 \mathrm{k}}-b-\mathrm{PBA}_{12 \mathrm{k}}$ films and $\mathrm{CsPbBr}_{3} @ \mathrm{PF}_{8 \mathrm{k}}-b-\mathrm{PBA}_{12 \mathrm{k}}$ composite fibers $(1 \mathrm{~g} / 400 \mu \mathrm{L})$.

The color-tunable light down-converters were successfully fabricated using a single layer of $\mathrm{CsPbBr}_{3} @ \mathrm{PF}_{8 \mathrm{k}}-b-\mathrm{PBA}_{12 \mathrm{k}}$ composite fiber on a commercial UV chip $\left(\lambda_{\max }=380 \mathrm{~nm}\right)$ and commission internationale de l'eclairage (CIE) is illustrated in Figure 4. Furthermore, the color of the light down-converter can be controlled by varying the QD/polymer ratio by 1:100, 1:200, and 1:400 $(1 \mathrm{~g} / 400 \mu \mathrm{L})$ (Figure 4). The insets in Figure 4 display the light down-converter with different correlated color temperatures (CCTs), which correspond to the emission images. The emissive intensity of perovskite becomes weaker when the ratio decreases. In other words, the higher intensity at $550 \mathrm{~nm}$ on green-color-emission is observed with an increasing perovskite QD blending ratio. It is because of the obvious energy transfer (physical processes) from commercial UV LED chip (donor) and PF-block (donor) to perovskite QD (acceptor), which is similar to some papers [38,44]. In this way, the CCTs and color can turn from green to blue. It is a novel and simple method of controlling the color by blending perovskite in the polymer fiber. 


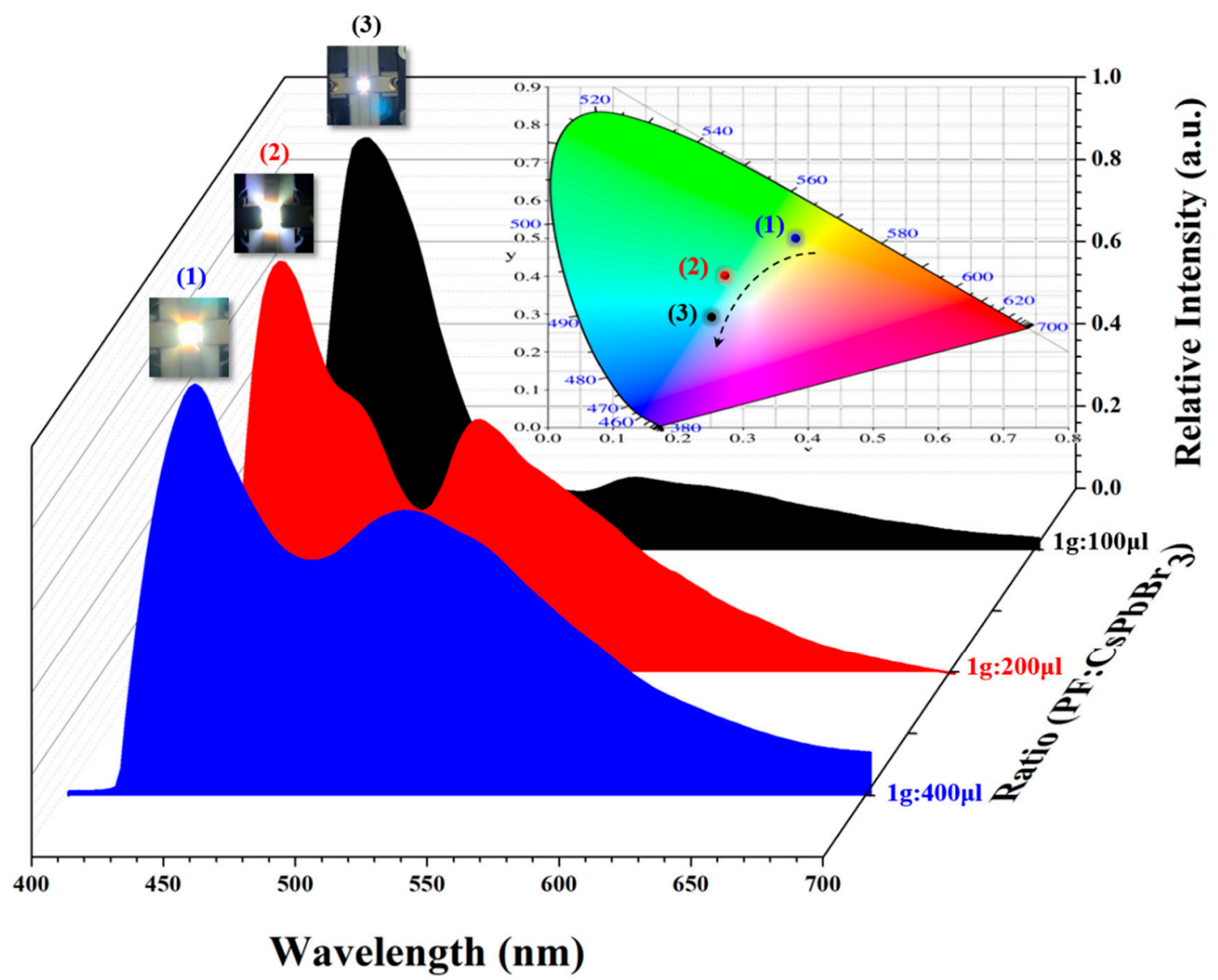

Figure 4. Emission spectra of different color light down-converter with CIE color coordinates obtained using $\mathrm{CsPbBr}_{3} @ \mathrm{PF}_{8 \mathrm{k}}-b-\mathrm{PBA}_{12 \mathrm{k}}$ composite fibers under UV chip (380 nm) excitation and an applied voltage of $3 \mathrm{~V}$. (Inset images show the light down-converter with an applied QD/polymer composite fiber ratio of 100:1, 200:1, and 400:1 $(\mu \mathrm{L} / \mathrm{g}))$.

\section{Conclusions}

We successfully synthesized rod-coil $\mathrm{PF}_{8 \mathrm{k}}-b-\mathrm{PBA}_{12 \mathrm{k}}$ block copolymers. Through the incorporation of a PBA soft segment, such a block copolymer is able to maintain high stretchability, which facilitates its application in a variety of functions, such as an electron-hole transport layer or emission layer in light down-converters. Furthermore, we utilized a simple electrospinning method to combine conjugated block copolymer with perovskite QDs to prepared light down-converters by single-layer fiber mats. In contrast to the multicolor stack and perovskite's halogen substitute methods, the light down-converter color can be tuned by varying the $\mathrm{QD} /$ polymer ratios and only using a single layer due to the double fluorescence combination. The results of the present study suggest that block copolymers combined with perovskite have the potential to achieve high stretchability as well as favorable fluorescent properties for versatile applications that require outstanding optical properties.

Supplementary Materials: The following are available online at http://www.mdpi.com/2073-4360/12/1/84/s1. ${ }^{1} \mathrm{H}-\mathrm{NMR}$ spectra of the polymers; FTIR of the PBA homopoymers; SEC profiles of the polymers; TGA curves, $\mathrm{UV}$-vis absorption, and PL emission spectrum of the polymers.

Funding: This research was founded by the Ministry of Science and Technology, Taiwan (Grant Number: MOST 106-2221-E-027-119-MY3). This research was also financially founded by the JSPS KAKENHI (Grant Number 19H02769), Frontier Chemistry Center (Hokkaido University), and the Photo-excitonix Project (Hokkaido University).

Conflicts of Interest: The authors declare no conflict of interest. 


\section{References}

1. Chikamatsu, M.; Nagamatsu, S.; Yoshida, Y.; Saito, K.; Yase, K.; Kikuchi, K. Solution-processed n-type organic thin-film transistors with high field-effect mobility. Appl. Phys. Lett. 2005, 87, 203504. [CrossRef]

2. Yu, X.; Rahmanudin, A.; Jeanbourquin, X.A.; Tsokkou, D.; Guijarro, N.S.; Banerji, N.; Sivula, K. Hybrid heterojunctions of solution-processed semiconducting 2D transition metal dichalcogenides. ACS Energy Lett. 2017, 2, 524-531. [CrossRef]

3. Van de Wetering, K.; Brochon, C.; Ngov, C.; Hadziioannou, G. Design and Synthesis of a Low Band Gap Conjugated Macroinitiator: Toward Rod-Coil Donor-Acceptor Block Copolymers. Macromolecules 2006, 39, 4289-4297. [CrossRef]

4. Yi, Z.; Wang, S.; Liu, Y. Design of high-mobility diketopyrrolopyrrole-based $\pi$-conjugated copolymers for organic thin-film transistors. Adv. Mater. 2015, 27, 3589-3606. [CrossRef] [PubMed]

5. Zhang, Y.-H.; Zhou, K.-G.; Xie, K.-F.; Zeng, J.; Zhang, H.-L.; Peng, Y. Tuning the electronic structure and transport properties of graphene by noncovalent functionalization: Effects of organic donor, acceptor and metal atoms. Nanotechnology 2010, 21, 065201. [CrossRef]

6. An, B.-K.; Gierschner, J.; Park, S.Y. $\pi$-Conjugated cyanostilbene derivatives: A unique self-assembly motif for molecular nanostructures with enhanced emission and transport. Acc. Chem. Res. 2011, 45, 544-554. [CrossRef]

7. Luo, C.; Kyaw, A.K.K.; Perez, L.A.; Patel, S.; Wang, M.; Grimm, B.; Bazan, G.C.; Kramer, E.J.; Heeger, A.J. General strategy for self-assembly of highly oriented nanocrystalline semiconducting polymers with high mobility. Nano Lett. 2014, 14, 2764-2771. [CrossRef]

8. Choi, S.; Lee, H.; Ghaffari, R.; Hyeon, T.; Kim, D.H. Recent advances in flexible and stretchable bio-electronic devices integrated with nanomaterials. Adv. Mater. 2016, 28, 4203-4218. [CrossRef]

9. Kim, D.-H.; Lu, N.; Ma, R.; Kim, Y.-S.; Kim, R.-H.; Wang, S.; Wu, J.; Won, S.M.; Tao, H.; Islam, A. Epidermal electronics. Science 2011, 333, 838-843. [CrossRef]

10. Rogers, J.A.; Someya, T.; Huang, Y. Materials and mechanics for stretchable electronics. Science 2010, 327, 1603-1607. [CrossRef]

11. Zhang, Y.; He, Z.; Jiang, S.; Gao, B.; Liu, Z.; Han, B.; Wang, H. Marine redox stratification during the early C ambrian (ca. 529-509 Ma) and its control on the development of organic-rich shales in $\mathrm{Y}$ angtze P latform. Geochem. Geophys. Geosyst. 2017, 18, 2354-2369.

12. Choi, M.K.; Yang, J.; Kang, K.; Kim, D.C.; Choi, C.; Park, C.; Kim, S.J.; Chae, S.I.; Kim, T.-H.; Kim, J.H. Wearable red-green-blue quantum dot light-emitting diode array using high-resolution intaglio transfer printing. Nat. Commun. 2015, 6, 7149. [CrossRef] [PubMed]

13. Kim, T.-H.; Lee, C.-S.; Kim, S.; Hur, J.; Lee, S.; Shin, K.W.; Yoon, Y.-Z.; Choi, M.K.; Yang, J.; Kim, D.-H. Fully stretchable optoelectronic sensors based on colloidal quantum dots for sensing photoplethysmographic signals. ACS Nano 2017, 11, 5992-6003. [CrossRef]

14. Son, D.; Chae, S.I.; Kim, M.; Choi, M.K.; Yang, J.; Park, K.; Kale, V.S.; Koo, J.H.; Choi, C.; Lee, M. Colloidal synthesis of uniform-sized molybdenum disulfide nanosheets for wafer-scale flexible nonvolatile memory. Adv. Mater. 2016, 28, 9326-9332. [CrossRef]

15. Song, J.K.; Son, D.; Kim, J.; Yoo, Y.J.; Lee, G.J.; Wang, L.; Choi, M.K.; Yang, J.; Lee, M.; Do, K. Wearable force touch sensor array using a flexible and transparent electrode. Adv. Funct. Mater. 2017, 27, 1605286. [CrossRef]

16. Choi, D.; Kim, H.; Persson, N.; Chu, P.-H.; Chang, M.; Kang, J.-H.; Graham, S.; Reichmanis, E. Elastomer-polymer semiconductor blends for high-performance stretchable charge transport networks. Chem. Mater. 2016, 28, 1196-1204. [CrossRef]

17. Kuo, C.-C.; Lin, C.-H.; Chen, W.-C. Morphology and photophysical properties of light-emitting electrospun nanofibers prepared from poly (fluorene) derivative/PMMA blends. Macromolecules 2007, 40, 6959-6966. [CrossRef]

18. Lee, Y.; Zhou, H.; Lee, T.-W. One-dimensional conjugated polymer nanomaterials for flexible and stretchable electronics. J. Mater. Chem. C 2018, 6, 3538-3550. [CrossRef]

19. Scott, J.I.; Xue, X.; Wang, M.; Kline, R.J.; Hoffman, B.C.; Dougherty, D.; Zhou, C.; Bazan, G.; O'Connor, B.T. Significantly increasing the ductility of high performance polymer semiconductors through polymer blending. ACS Appl. Mater. Interface 2016, 8, 14037-14045. [CrossRef] 
20. Shin, M.; Oh, J.Y.; Byun, K.E.; Lee, Y.J.; Kim, B.; Baik, H.K.; Park, J.J.; Jeong, U. Polythiophene nanofibril bundles surface-embedded in elastomer: A route to a highly stretchable active channel layer. Adv. Mater. 2015, 27, 1255-1261. [CrossRef]

21. Song, E.; Kang, B.; Choi, H.H.; Sin, D.H.; Lee, H.; Lee, W.H.; Cho, K. Stretchable and transparent organic semiconducting thin film with conjugated polymer nanowires embedded in an elastomeric matrix. Adv. Electron. Mater. 2016, 2, 1500250. [CrossRef]

22. Peng, R.; Pang, B.; Hu, D.; Chen, M.; Zhang, G.; Wang, X.; Lu, H.; Cho, K.; Qiu, L. An ABA triblock copolymer strategy for intrinsically stretchable semiconductors. J. Mater. Chem. C 2015, 3, 3599-3606. [CrossRef]

23. Wu, H.-C.; Hung, C.-C.; Hong, C.-W.; Sun, H.-S.; Wang, J.-T.; Yamashita, G.; Higashihara, T.; Chen, W.-C. Isoindigo-based semiconducting polymers using carbosilane side chains for high performance stretchable field-effect transistors. Macromolecules 2016, 49, 8540-8548. [CrossRef]

24. Oh, J.Y.; Rondeau-Gagné, S.; Chiu, Y.-C.; Chortos, A.; Lissel, F.; Wang, G.-J.N.; Schroeder, B.C.; Kurosawa, T.; Lopez, J.; Katsumata, T. Intrinsically stretchable and healable semiconducting polymer for organic transistors. Nat. Commun. 2016, 539, 411. [CrossRef] [PubMed]

25. Wang, J.-T.; Saito, K.; Wu, H.-C.; Sun, H.-S.; Hung, C.-C.; Chen, Y.; Isono, T.; Kakuchi, T.; Satoh, T.; Chen, W.-C. High-performance stretchable resistive memories using donor-acceptor block copolymers with fluorene rods and pendent isoindigo coils. NPG Asia Mater. 2016, 8, e298. [CrossRef]

26. Wang, J.-T.; Takshima, S.; Wu, H.-C.; Shih, C.-C.; Isono, T.; Kakuchi, T.; Satoh, T.; Chen, W.-C. Stretchable conjugated rod-coil poly (3-hexylthiophene)-block-poly (butyl acrylate) thin films for field effect transistor applications. Macromolecules 2017, 50, 1442-1452. [CrossRef]

27. Hsieh, H.-C.; Hung, C.-C.; Watanabe, K.; Chen, J.-Y.; Chiu, Y.-C.; Isono, T.; Chiang, Y.-C.; Reghu, R.R.; Satoh, T.; Chen, W.-C. Unraveling the stress effects on the optical properties of stretchable rod-coil polyfluorene-poly( $n$-butyl acrylate) block copolymer thin films. Polym. Chem. 2018, 9, 3820-3831. [CrossRef]

28. Hung, C.C.; Nakahira, S.; Chiu, Y.C.; Isono, T.; Wu, H.C.; Watanabe, K.; Chiang, Y.C.; Takashima, S.; Borsali, R.; Tung, S.H.; et al. Control over Molecular Architectures of Carbohydrate-Based Block Copolymers for Stretchable Electrical Memory Devices. Macromolecules 2018, 51, 4966-4975. [CrossRef]

29. Wen, H.-F.; Wu, H.-C.; Aimi, J.; Hung, C.-C.; Chiang, Y.-C.; Kuo, C.-C.; Chen, W.-C. Soft poly(butyl acrylate) side chains toward Intrinsically stretchable polymeric semiconductors for field-effect transistor applications. Macromolecules 2017, 50, 4982-4992. [CrossRef]

30. Neher, D. Polyfluorene homopolymers: Conjugated liquid-crystalline polymers for bright blue emission and polarized electroluminescence. Macromol. Rapid Comm. 2001, 22, 1365-1385. [CrossRef]

31. Zhou, H.; Yang, L.; You, W. Rational design of high performance conjugated polymers for organic solar cells. Macromolecules 2012, 45, 607-632. [CrossRef]

32. Lu, S.; Liu, T.; Ke, L.; Ma, D.-G.; Chua, S.-J.; Huang, W. Polyfluorene-based light-emitting rod- coil block copolymers. J. Macromol. 2005, 38, 8494-8502. [CrossRef]

33. Saito, K.; Isono, T.; Sun, H.-S.; Kakuchi, T.; Chen, W.-C.; Satoh, T. Rod-coil type miktoarm star copolymers consisting of polyfluorene and polylactide: Precise synthesis and structure-morphology relationship. Polym. Chem. 2015, 6, 6959-6972. [CrossRef]

34. Jin, G.; Xia, L.; Liu, Z.; Lin, H.; Ling, J.; Wu, H.; Hou, L.; Mo, Y. Highly efficient and stable blue polymer light emitting diodes based on polysilafluorenes with pendent hole transporting groups. J. Mater. Chem. C 2016, 4, 905-913. [CrossRef]

35. Smith, K.A.; Lin, Y.-H.; Dement, D.B.; Strzalka, J.; Darling, S.B.; Pickel, D.L.; Verduzco, R. Synthesis and crystallinity of conjugated block copolymers prepared by click chemistry. Macromolecules 2013, 46, 2636-2645. [CrossRef]

36. Bade, S.G.R.; Shan, X.; Hoang, P.T.; Li, J.; Geske, T.; Cai, L.; Pei, Q.; Wang, C.; Yu, Z. Stretchable Light-Emitting Diodes with Organometal-Halide-Perovskite-Polymer Composite Emitters. Adv. Mater. 2017, 29, 1607053. [CrossRef]

37. Chou, S.-Y.; Ma, R.; Li, Y.; Zhao, F.; Tong, K.; Yu, Z.; Pei, Q. Transparent Perovskite Light-Emitting Touch-Responsive Device. ACS Nano 2017, 11, 11368-11375. [CrossRef]

38. Lin, C.C.; Jiang, D.-H.; Kuo, C.-C.; Cho, C.-J.; Tsai, Y.-H.; Satoh, T.; Su, C. Water-resistant efficient stretchable perovskite-embedded fiber membranes for light-emitting diodes. ACS Appl. Mater. Interface 2018, 10, 2210-2215. [CrossRef] 
39. Sultana, A.; Alam, M.M.; Sadhukhan, P.; Ghorai, U.K.; Das, S.; Middya, T.R.; Mandal, D. Organo-lead halide perovskite regulated green light emitting poly(vinylidene fluoride) electrospun nanofiber mat and its potential utility for ambient mechanical energy harvesting application. Nano Energy 2018, 49, 380-392. [CrossRef]

40. Hu, T.; Smith, M.D.; Dohner, E.R.; Sher, M.J.; Wu, X.; Trinh, M.T.; Fisher, A.; Corbett, J.; Zhu, X.Y.; Karunadasa, H.I.; et al. Mechanism for broadband white-light emission from two-dimensional (110) hybrid perovskites. J. Phys. Chem. Lett. 2016, 7, 2258-2263. [CrossRef]

41. Mao, L.; Wu, Y.; Stoumpos, C.C.; Wasielewski, M.R.; Kanatzidis, M.G. White-light emission and structural distortion in new corrugated two-dimensional lead bromide perovskites. J. Am. Chem. Soc. 2017, 139, 5210-5215. [CrossRef] [PubMed]

42. Li, X.; Wu, Y.; Zhang, S.; Cai, B.; Gu, Y.; Song, J.; Zeng, H. CsPbX3 quantum dots for lighting and displays: Room-temperature synthesis, photoluminescence superiorities, underlying origins and white light-emitting diodes. Adv. Funct. Mater. 2016, 26, 2435-2445. [CrossRef]

43. Wang, Y.; He, J.; Chen, H.; Chen, J.; Zhu, R.; Ma, P.; Towers, A.; Lin, Y.; Gesquiere, A.J.; Wu, S.T. Ultrastable, highly luminescent organic-inorganic perovskite-polymer composite films. Adv. Mater. 2016, 28, 10710-10717. [CrossRef]

44. Zhou, Q.; Bai, Z.; Lu, W.g.; Wang, Y.; Zou, B.; Zhong, H. In situ fabrication of halide perovskite nanocrystal-embedded polymer composite films with enhanced photoluminescence for display backlights. Adv. Mater. 2016, 28, 9163-9168. [CrossRef]

45. Jiang, D.-H.; Chiu, P.-C.; Cho, C.-J.; Veeramuthu, L.; Tung, S.-H.; Satoh, T.; Chiang, W.-H.; Cai, X.; Kuo, C.-C. Facile 3D Boron Nitride Integrated Electrospun Nanofibrous Membranes for Purging Organic Pollutants. Nanomaterials 2019, 9, 1383. [CrossRef]

46. Jiang, D.-H.; Tsai, P.-C.; Kuo, C.-C.; Jhuang, F.-C.; Guo, H.-C.; Chen, S.-P.; Liao, Y.-C.; Satoh, T.; Tung, S.-H. Facile Preparation of $\mathrm{Cu} / \mathrm{Ag}$ Core/Shell Electrospun Nanofibers as Highly Stable and Flexible Transparent Conductive Electrodes for Optoelectronic Devices. ACS Appl. Mater. Interface 2019, 11, 10118-10127. [CrossRef]

47. Jiang, D.-H.; Tsai, Y.-H.; Veeramuthu, L.; Liang, F.-C.; Chen, L.-C.; Lin, C.C.; Satoh, T.; Tung, S.-H.; Kuo, C.-C. Novel ultra-stable and highly luminescent white light-emitting diodes from perovskite quantum dots-Polymer nanofibers through biaxial electrospinning. APL Mater. 2019, 7, 111105. [CrossRef]

48. Veeramuthu, L.; Chen, B.-Y.; Tsai, C.-Y.; Liang, F.-C.; Venkatesan, M.; Jiang, D.-H.; Chen, C.-W.; Cai, X.; Kuo, C.-C. Novel stretchable thermochromic transparent heaters designed for smart window defroster applications by spray coating silver nanowire. RSC Adv. 2019, 9, 35786-35796. [CrossRef]

49. Veeramuthu, L.; Li, W.-L.; Liang, F.-C.; Cho, C.-J.; Kuo, C.-C.; Chen, W.-C.; Lin, J.-H.; Lee, W.-Y.; Wang, C.-T.; Lin, W.-Y. Smart garment energy generators fabricated using stretchable electrospun nanofibers. React. Funct. Polym. 2019, 142, 96-103. [CrossRef]

50. Cho, C.-J.; Lu, S.-T.; Kuo, C.-C.; Liang, F.-C.; Chen, B.-Y.; Chu, C.-C. Pyrene or rhodamine derivative-modified surfaces of electrospun nanofibrous chemosensors for colorimetric and fluorescent determination of $\mathrm{Cu} 2+$, Hg2+, and pH. React. Funct. Polym. 2016, 108, 137-147. [CrossRef]

51. Liang, F.-C.; Chang, Y.-W.; Kuo, C.-C.; Cho, C.-J.; Jiang, D.-H.; Jhuang, F.-C.; Rwei, S.-P.; Borsali, R. A mechanically robust silver nanowire-polydimethylsiloxane electrode based on facile transfer printing techniques for wearable displays. Nanoscale 2019, 11, 1520-1530. [CrossRef] [PubMed]

52. Sehaqui, H.; Morimune, S.; Nishino, T.; Berglund, L.A. Stretchable and strong cellulose nanopaper structures based on polymer-coated nanofiber networks: An alternative to nonwoven porous membranes from electrospinning. Biomacromolecules 2012, 13, 3661-3667. [CrossRef] [PubMed]

53. Wang, X.; Zhang, Y.; Zhang, X.; Huo, Z.; Li, X.; Que, M.; Peng, Z.; Wang, H.; Pan, C. A highly stretchable transparent self-powered triboelectric tactile sensor with metallized nanofibers for wearable electronics. Adv. Mater. 2018, 30, 1706738. [CrossRef] [PubMed]

(C) 2020 by the authors. Licensee MDPI, Basel, Switzerland. This article is an open access article distributed under the terms and conditions of the Creative Commons Attribution (CC BY) license (http://creativecommons.org/licenses/by/4.0/). 